\title{
Meiotic pairing of $B$ chromosomes, multiple sexual system, and Robertsonian fusion in the red brocket deer Mazama americana (Mammalia, Cervidae)
}

\author{
C.I. Aquino ${ }^{1}$, V.V. Abril ${ }^{1,2}$ and J.M.B. Duarte ${ }^{2}$ \\ ${ }^{1}$ Núcleo de Pesquisa e Conservação de Cervídeos, Departamento de Zootecnia, \\ Faculdade de Ciências Agrárias e Veterinárias, Universidade Estadual Paulista, \\ Campus de Jaboticabal, Jaboticabal, SP, Brasil \\ ${ }^{2}$ Programa de Pós-Graduação em Genética e Melhoramento Animal, \\ Faculdade de Ciências Agrárias e Veterinárias, Universidade Estadual Paulista, \\ Campus de Jaboticabal, Jaboticabal, SP, Brasil
}

Corresponding author: V.V. Abril

E-mail: vanessa.abril@gmail.com

Genet. Mol. Res. 12 (3): 3566-3574 (2013)

Received August 31, 2012

Accepted December 19, 2012

Published September 13, 2013

DOI http://dx.doi.org/10.4238/2013.September.13.1

\begin{abstract}
Deer species of the genus Mazama show significant inter- and intraspecific chromosomal variation due to the occurrence of rearrangements and B chromosomes. Given that carriers of aneuploidies and structural rearrangements often show anomalous chromosome pairings, we here performed a synaptonemal complex analysis to study chromosome pairing behavior in a red brocket deer (Mazama americana) individual that is heterozygous for a Robertsonian translocation, is a B chromosome carrier, and has a multiple sex chromosome system $\left(\mathrm{XY}_{1} \mathrm{Y}_{2}\right)$. The synaptonemal complex in spermatocytes showed normal chromosome pairings for all chromosomes, including the autosomal and sex trivalents. The electromicrographs showed homology among B chromosomes since they formed bivalents, but they also appeared as univalents, indicating their anomalous behavior and non-Mendelian
\end{abstract}


segregation. Thus, synaptonemal complex analysis is a useful tool to evaluate the role of $\mathrm{B}$ chromosomes and rearrangements during meiosis on the intraspecific chromosomal variation that is observed in the majority of Mazama species.

Key words: Cervidae; Synaptonemal complex; Centric fusion; $\mathrm{XY}_{1} \mathrm{Y}_{2}$; B chromosome

\section{INTRODUCTION}

For some deer species, the study of chromosomes can provide important tools for taxonomy, management, and conservation, since intraspecific karyotypic variation has a limit imposed by meiotic stability in the production of gametes. Variations in the number and structure of the chromosomal sets of 2 individuals can result in reduced fertility in their descendants. This is especially relevant for Neotropical deer of the genus Mazama, which demonstrates similar morphology but major cytogenetic differences due to inter- and intraspecific polymorphisms (Duarte and Jorge, 1996, 2003; Abril and Duarte, 2008; Duarte et al., 2008; Abril et al., 2010). One possible explanation for the frequent occurrence of these polymorphisms is the chromosomal fragility observed in Mazama (Vargas-Munar et al., 2010), which increases the tendency of chromosomal breakages (Glover and Stein, 1988).

During meiotic prophase I, homologous chromosomes interact with one another and form bivalents. At the zygotene stage, the structure of the synaptonemal complex begins to form, providing the basis for the correct disjunction of chromosomes at meiosis and genetic recombination between homologous chromosomes (Bogdanov, 2003).

Anomalous pairings in animals with chromosomal rearrangements may result in spermatogenic arrest, leading to the production of unbalanced gametes and a reduction in fertility (Switonski and Stranzinger, 1998). The main distinction between homozygotes and heterozygotes with respect to centric fusions is determined by the presence of trivalents in heterozygotes at the pachytene and diplotene stages (Wallace et al., 1992).

B chromosomes, also called accessory or supernumerary chromosomes, show particular meiotic behaviors. Dispensable to the individual, they have non-Mendelian segregation and high polymorphism. Inter- and intra-individual variation in the number of B chromosomes appears to be due to their irregular behavior during meiosis and mitosis (Jones and Rees, 1982). Synaptonemal complex analyses of mammals carrying B chromosomes have shown that synaptic behavior depends on the number of these chromosomes in the spermatocytes. Univalents, bivalents, trivalents, and/or bivalents + univalents have been observed when 1, 2, or $3 \mathrm{~B}$ chromosomes, respectively, were present in the cell (Switonski et al., 1987a; Shi et al., 1988).

In this study, we focus on chromosomal variation in the red brocket deer (Mazama americana). Cytogenetic and molecular studies of several populations of this species throughout Brazil showed that many karyotypic variants exist with different geographical distributions. These variants were classified as the following cytotypes, which represent significantly differentiated populations (Sarria-Perea, 2004; Duarte et al., 2008; Abril et al., 2010): Paraná $(2 \mathrm{n}=52 \mathrm{\rho} / 53 \hat{\partial}+3-4 \mathrm{~B}$ and $\mathrm{FN}=56)$; Carajás $(2 \mathrm{n}=50$ \% $/ 51 \hat{\partial}+3-4 \mathrm{~B}$ and $\mathrm{FN}=54)$; Santarém

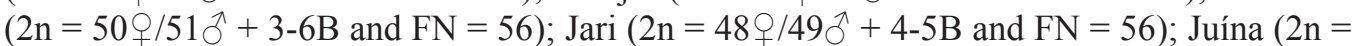
$449 / 45 \hat{\jmath}+3-6 \mathrm{~B}$ and $\mathrm{FN}=48)$; Rondônia $(2 \mathrm{n}=42$ q $/ 43 \hat{\jmath}+3-5 \mathrm{~B}$ and $\mathrm{FN}=46)$; and Acre $(2 \mathrm{n}$ 
$=46$ P $/ 47 \hat{\delta}+3-4 \mathrm{~B}$ and $\mathrm{FN}=56)$. The evolutionary processes and the chromosomal differentiation of this species have mainly been driven by tandem and centric fusion (Abril et al., 2010).

Moreover, a multiple sex chromosome system, $\mathrm{XX} / \mathrm{XY}_{1} \mathrm{Y}_{2}$, was first described in this species after a G-banding study of animals from Brazil (Sarria-Perea, 2004). This multiple sex chromosome system possibly arose when an X-autosome translocation took place in an ancestor of the species.

B chromosome variation has been observed in several species of Neotropical deer (Duarte and Jorge, 2003; Abril and Duarte, 2008). For M. americana, B chromosomes appear to be an important source of inter- and intra-individual variation (Sarria-Perea, 2004; Abril et al., 2010). However, no study has yet investigated meiotic behavior in Neotropical deer species. Rearrangements, such as centric fusions, tandem fusions, and inversions, are responsible for producing high intraspecific chromosomal variation, but the impact on such carriers when heterozygous remains unknown (Abril and Duarte, 2008; Abril et al., 2010).

In this study, we investigated the process of chromosome synapsis in 1 male M. americana with a Robertsonian heterozygous chromosome pair, B chromosomes, and a multiple sex chromosome system $\left(\mathrm{XY}_{1} \mathrm{Y}_{2}\right)$.

\section{MATERIAL AND METHODS}

One adult male $M$. americana (T269) was analyzed while maintained in captivity at the facilities of the Deer Research and Conservation Center (Núcleo de Pesquisa e Conservação de Cervídeos, NUPECCE), Jaboticabal, SP, Brazil. This deer was wild-born in the city of Buritis in the State of Rondônia, Brazil.

Mitotic chromosome preparations and staining were performed using methods described in Verma and Babu (1995), G-banding was accomplished according to methods described in Seabright (1971), and Ag-NOR staining was accomplished according to the Howell and Black (1980) technique. Metaphases were analyzed with optical microscopy (Olympus BX60) with a digital camera (Olympus Camedia C5060) and the images were edited using the Adobe Photoshop CS2 software.

Synaptonemal complex analysis was performed as described by Wise and Nail (1987), with modifications. The testicular material was obtained by needle biopsy and placed in the Hanks saline solution. For cell suspension preparation, the material was placed in a few drops of Hanks solution over an inverted Petri dish covered with a parafilm layer and carefully minced with a razor blade. The cell suspension was transferred to a centrifuge tube placed on ice. After centrifugation for about $13 \mathrm{~min}$, the supernatant was discarded, the pellet was diluted to the desired concentration, and 1 drop was transferred to a slide covered with thin triacetate film ( $1 \%$ chloroform). Two drops of $0.03 \%$ Triton X100, $\mathrm{pH} 7.5$, were added and approximately $13 \mathrm{~min}$ later, 6 drops of fixative solution $[4 \%(\mathrm{w} / \mathrm{v})$ paraformaldehyde] were added and the slide was shaken in order to mix the solutions. The slides were then laid flat on a support and allowed to dry overnight at $45^{\circ} \mathrm{C}$. After drying, the slides were rinsed for $1 \mathrm{~min}$ in a $0.4 \%$ "Photoflo" solution (Kodak Co.) followed by distilled water, left to dry in a vertical position and then silver-stained (Sherman et al., 1992). After light microscope analysis, the meiotic cells were transferred to 50 mesh copper grids while covered with triacetate film. Electron microscopic analyses were performed at $80 \mathrm{kV}$ with a Phillips EM301 instrument. Photographs of 4 cells were taken. 


\section{RESULTS}

The $M$. americana male analyzed (T269) showed $2 \mathrm{n}=42$ and $\mathrm{FN}=46$ and presented a centric fusion in heterozygous form between chromosomes 7 and 20, as well as variation in the number of $\mathrm{B}$ chromosomes (2 to 5) and an $\mathrm{X}$-autosome fusion, resulting in a multiple sex chromosome system $\left(\mathrm{XY}_{1} \mathrm{Y}_{2}\right)$ (Figure 1).
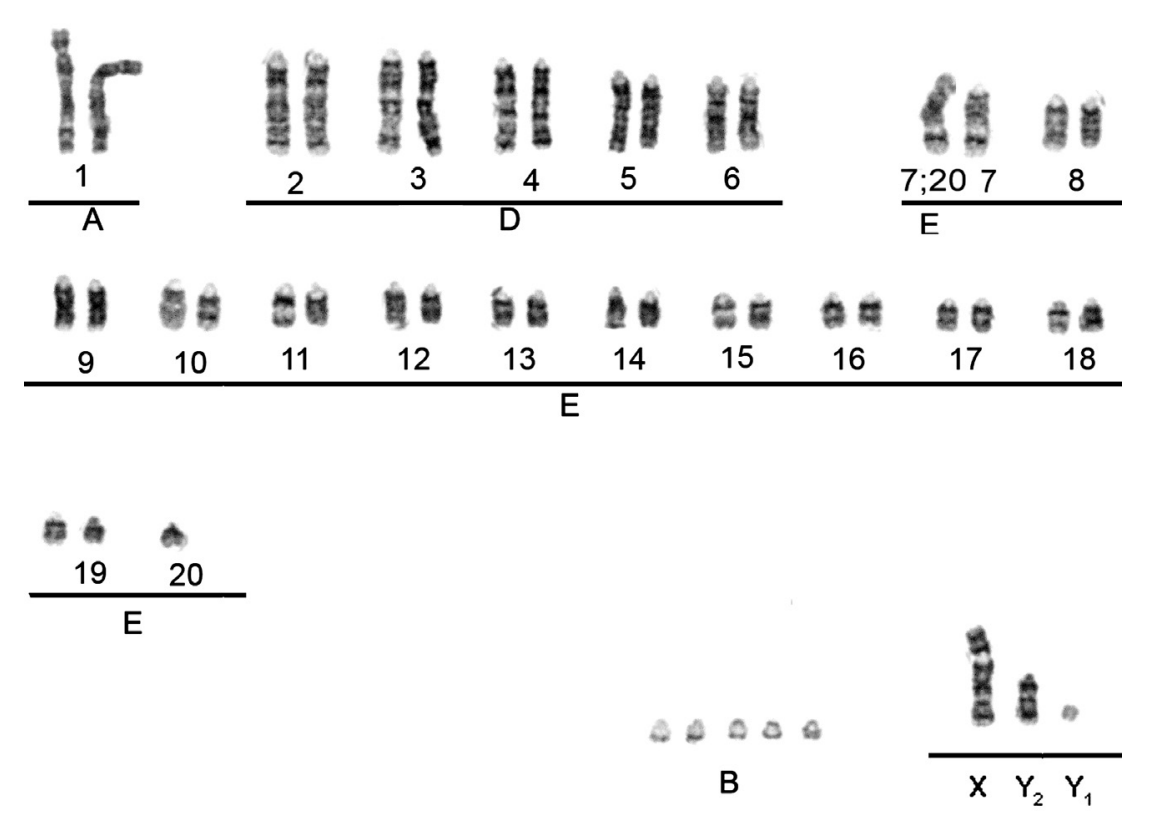

Figure 1. G-banded karyotype of a Mazama americana (T269) male $(2 \mathrm{n}=42+5 \mathrm{~B} ; \mathrm{FN}=46)$.

Due to the quality of biopsy sampling, it was only possible to analyze 4 meiotic cells. We found complete pairing of the autosomal chromosomes in 2 of the 4 cells, which were characterized as being in the substage of pachytene (Figure $2 \mathrm{a}$ and $\mathrm{b}$ ). In the third cell, it was apparent that synapsis was not complete and the extremities of some chromosomes were not paring, indicating that the cell was either in the late zygotene or in the early pachytene stage (Figure 2c). In the fourth cell analyzed, the chromosomes were superposed, which made analysis difficult, but we were nevertheless able to classify it as being in early pachytene due to the high number of bivalents (Figure 2d).

The synaptonemal complex karyotype was prepared from one of the cells analyzed (Figures 2a). This cell contained 18 autosomal bivalents, 1 autosomal trivalent due to a centric fusion between chromosomes 7 and 20, the sexual trivalent, and 2 bivalents formed by pairings of $4 \mathrm{~B}$ chromosomes (Figure 3). When mitotic chromosomes were subjected to Ag-NOR staining, 2 pairs were identified as carriers of active nucleolar regions. Pair 1 showed an interstitial mark on the long arm and pair 8 showed a terminal mark. These same NOR-bearing chromosomes were also identifiable in the meiotic analyses (Figure 3). 

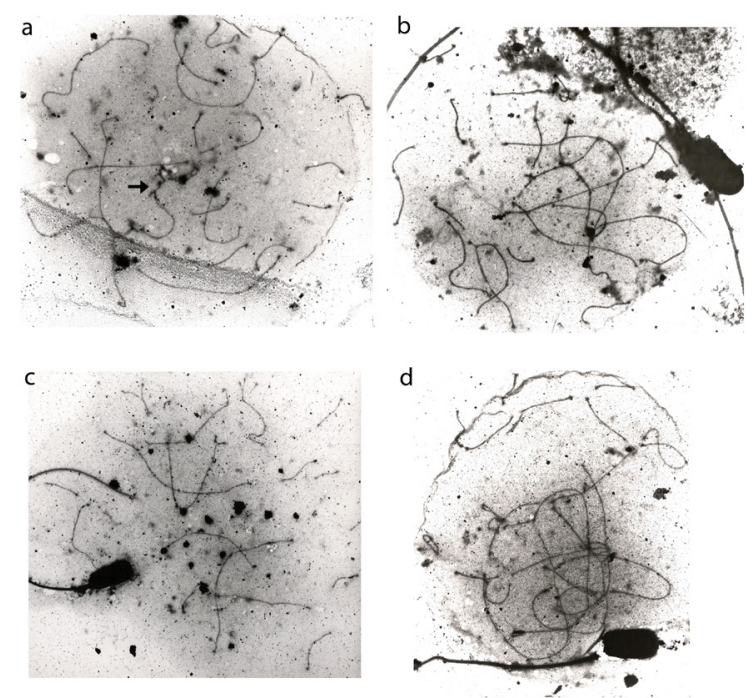

Figure 2. Silver-stained electron microphotographs of primary spermatocytes of red brocket deer. a. Cell in pachytene substage with synapsis almost completed, with exception of autosomal and sexual trivalent (arrow) 4875X. b. Cell in pachytene substage with completed synapsis of all chromosomes - 4875X. c. Cell in late zygotene or early pachytene substage with many unpaired extremities - 3675X. d. Pachytenic cell with many superposed chromosomes - 5200X.

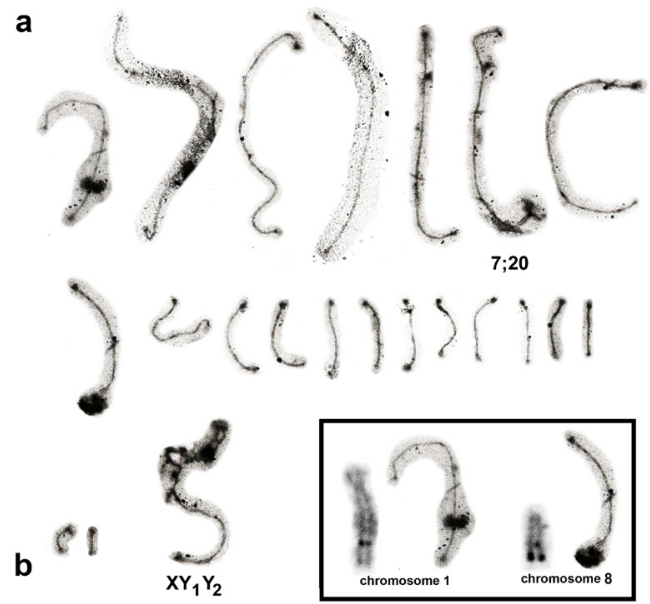

Figure 3. Synaptonemal complex karyotype of red brocket deer. Chromosomes have been arranged according to the system used for mitotic chromosomes. a. Note that there are 18 autosomal bivalents, 1 autosomal trivalent $(7 ; 20), 1$ sexual trivalent $\left(\mathrm{XY}_{1} \mathrm{Y}_{2}\right)$, and 2 bivalents formed by B chromosomes. Detailed view of NOR-bearing autosomal pairs (chromosomes 1 and 8) showing intersticial localization in pair 1 and terminal localization in pair 8. b. Identification of sex chromosomes $\left(\mathrm{X}, \mathrm{Y}_{1}\right.$, and $\left.\mathrm{Y}_{2}\right)$ on the meiotic trivalent.

The chromosomes involved in centric fusion appeared as trivalent during pachytene. Cells with complete synapsis between chromosomes had nonhomologous pairings in the centromeric region between the unfused chromosomes of the rearrangement (7 and 20) (Figure 2a 
and $\mathrm{b}$ and Figure $4 \mathrm{a}$ and $\mathrm{b}$ ). In contrast, these chromosomes were unpaired in this same region in the cell classified as late zygotene or early pachytene (Figure $2 \mathrm{c}$ and Figure $4 \mathrm{c}$ and $\mathrm{d}$ ).
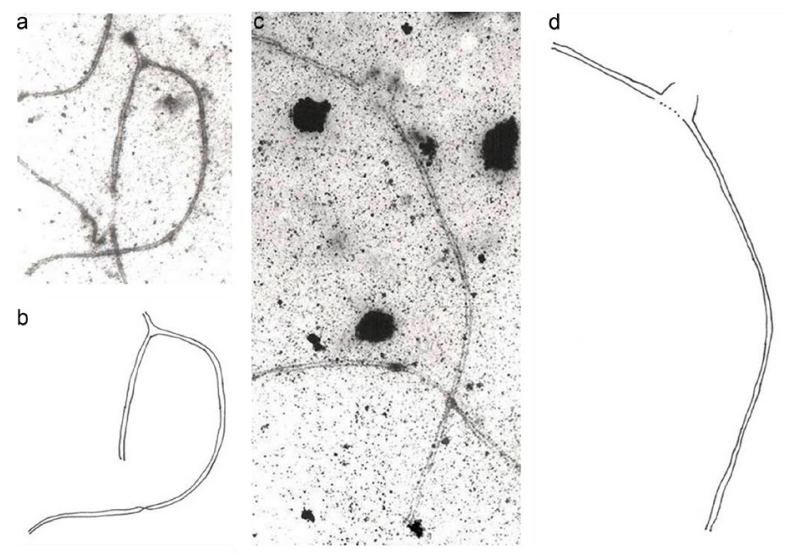

Figure 4. Two different examples of autosomal trivalent pairing. a. and b. Nonhomologous pairing in the centromeric region between the unfused chromosomes of rearrangement (7 and 20). c. and d. Autosomal trivalent with centromeric region of acrocentric chromosomes unpaired.

Regarding the multiple sex chromosome system, $\mathrm{XY}_{1} \mathrm{Y}_{2}$, a trivalent configuration was also identified in the pairing of these chromosomes due to an $\mathrm{X}$-autosome translocation that occurred in an ancestor of the species (Figure 5). As expected, $\mathrm{Y}_{1}$, which is unique to this species, partially paired with the $\mathrm{X}$ chromosome only in the pseudoautosomal region, while $\mathrm{Y}_{2}$, the ancestral autosome, was completely associated with the distal third of the long arm of X. A comparison between mitotic and meiotic sexual chromosomes allowed correct identification of sex chromosomes in the trivalent (Figure 5b).
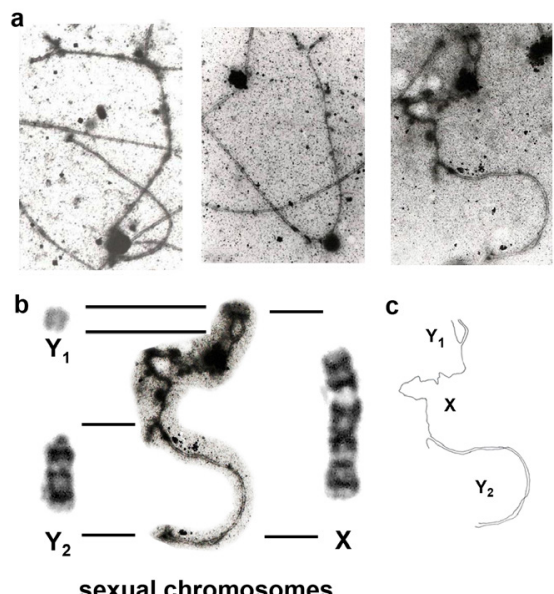

c

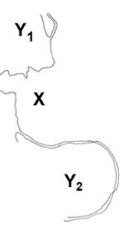

sexual chromosomes

Figure 5. Pairing of multiple sexual chromosomes $\left(X_{1} Y_{2}\right)$. a. Sexual trivalents. b. Comparison of meiotic trivalent with mitotic sexual chromosomes. c. Schematic design of the chromosome pairing observed in $\mathbf{b}$. Pairing of $\mathrm{X}$ and $\mathrm{Y}_{1}$ chromosomes occurs only in the pseudoautosomal region in one of the extremities of $\mathrm{X}$ chromosome and part of $Y_{1}$ remains free. $Y_{2}$ chromosome appears totally paired in another extremity of $X$. 
B chromosomes were found as bivalents, as autopaired univalents, and as univalents (Figure 6a-d). They were classified as B chromosomes after the identification of 18 autosomal bivalents and 2 trivalents (autosomal and sexual), due to their numeric variation among several cells, and due to their smaller length relative to all chromosomes.
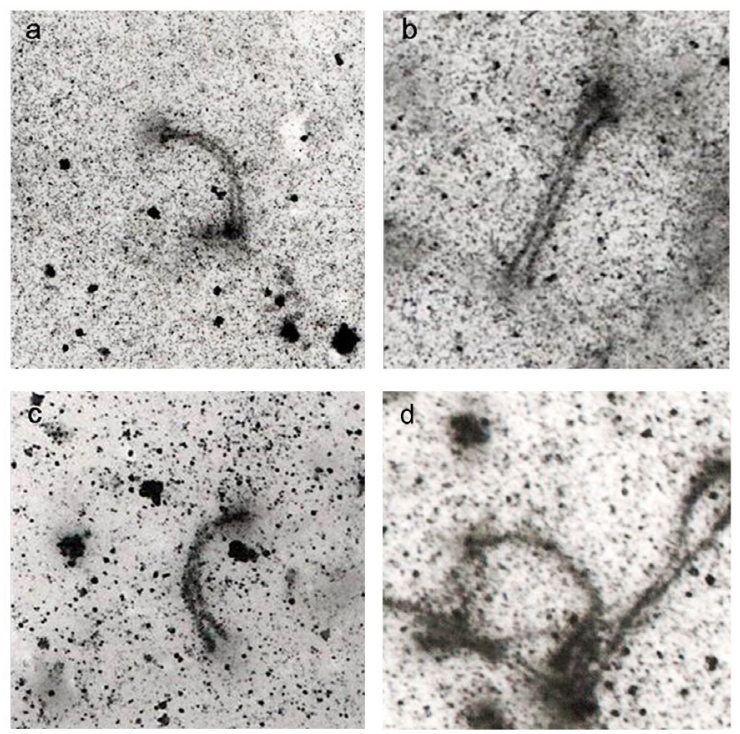

Figure 6. Different configurations found for pairing of B chromosomes. a. and b. Bivalents; c. autopaired univalents; d. unpaired univalents.

\section{DISCUSSION}

The high incidence of polymorphism in M. americana and other species of this genus has incited questions as to whether such polymorphisms could lead reproductive isolation due to failures in meiotic pairing (Duarte and Jorge, 1996, 2003; Duarte et al., 2008; Abril and Duarte, 2008). Wallace et al. (1992) indicated that in the wild house mouse, a single Robertsonian heterozygote could have near normal fertility.

Although few cells were analyzed in this study, the pairing of autosomes involved with centric fusion could nonetheless demonstrate that the formation of unbalanced gametes is highly unlikely, since this trivalent usually had a single side arm at the position of the centromeres as a result of the nonhomologous pairing of the acrocentrics. However, the likelihood of the production of unbalanced gametes increases with the accumulation of rearrangements in heterozygous form (Wallace et al., 2002). This association could be confirmed with metaphase II analysis if homologous pairs already appear to be separated, but this analysis could not be executed for this study. However, the fertility of this male could nonetheless be demonstrated, since it had produced 4 descendants at the time of this publication.

Switonski et al. (1987a) suggested that the absence of pairing in the centromere region of rearranged chromosomes could indicate that pairing was initiated in the telomere region and the centromere region was the last segment in which pairing could occur. The absence of pair- 
ing between the proximal regions of chromosomes 7 and 20 and the rearranged chromosome $7 ; 20$ could be due to this process, or alternatively, due to the lack of homology in this region, since the translocated chromosome may have lost its centromere region.

The results obtained in relation to B chromosomes corroborated results of previous studies (Switonski et al., 1987b), given the observation of univalents and bivalents. The presence of bivalents among the B chromosomes indicates that they are, at least partially, homologous. In some cells, the presence of B chromosome bivalents was observed, while in others, only one univalent was identified, confirming their anomalous behavior and non-Mendelian segregation.

The observed multiple sex chromosome system, $\mathrm{XY}_{1} \mathrm{Y}_{2}$, has also previously been described by Pathak and Lin (1981) in Muntiacus muntjak. Neitzel (1987) suggested the possibility of this type of rearrangement in a female M. americana born in Paraguay. Furthermore, analysis of chromosome banding confirmed the existence of the multiple sex chromosomes $\left(\mathrm{XY}_{1} \mathrm{Y}_{2}\right)$ in all analyzed cytotypes of $M$. americana: Paraná, Santarém, Carajás, Jari, Juína, and Rondônia (Sarria-Perea, 2004; Abril et al., 2010). The present study goes a step further, demonstrating the existence of this $\mathrm{X}$-autosome fusion using both chromosome banding and meiotic pairing analyses. The pairing of $X$ and $Y_{1}$ chromosomes occurs only in the pseudoautosomal region at one of the extremities of the $\mathrm{X}$ chromosome, in which part of $\mathrm{Y}_{1}$ remains free while the $Y_{2}$ chromosome appears to be totally paired with another extremity of $X$. This pairing suggests that during separation from $X$ in anaphase $I$, the $Y_{1}$ and $Y_{2}$ chromosomes migrate together to the same cell. Partial synapsis between the $\mathrm{X}$ and $\mathrm{Y}$ chromosomes during male meiosis is the rule among eutherian mammals, although there are a few exceptions, mainly involving species with particularly large $\mathrm{X}$ and $\mathrm{Y}$ chromosomes with large blocks of heterochromatin (Solari, 1974; Solari and Pigozzi, 1994).

In Sorex araneus, cells at the mid-pachytene stage showed that a differentiated region of the $\mathrm{X}$ became visible as a thickened and darkly staining segment with excrescences attached (Pack et al., 1993). This feature is characteristic of the unpaired region of the X (Solari, 1974) and it was observed here in the sex chromosomes of the red brocket deer (Figure 5) and previously in other mammal species, such as Artibeus lituratus (Solari and Pigozzi, 1994), Cebus apella paraguayanus (Mudry et al., 2001), and Muntiacus muntjak (Pathak and Lin, 1981).

Synaptonemal complex analysis is particularly valuable since the observation of intraspecific chromosome variation due to rearrangements in the majority of Mazama species could be responsible for failures in gametogenesis in specific situations, which could ultimately lead to significant declines in populations or of the species as a whole (Abril and Duarte, 2008). Therefore, the study of meiotic pairing in captive animals can be used to predict the probability of reduced fertility when rearrangements in the heterozygous condition are accumulated in one individual, further benefiting in situ conservation work.

In the case of $M$. americana, the tendency for chromosomal fragility (Vargas-Munar et al., 2010), combined with isolation in refuges (Duarte et al., 2008), could explain the existence of numerous karyotypic variants observed in Brazil (Abril et al., 2010). These variants could even be deemed separate species if hybrid sterility among them was demonstrated. Synaptonemal complex analysis could therefore be a determining factor in resolving the variation of this species.

In summary, the present analysis of a deer carrying one centric fusion suggests that this rearrangement has been well supported and has not affected fertility. When it becomes possible to define the level of chromosome variation that affects meiotic pairing, we will be close to defining the number of distinct Mazama species currently present in Brazil. 


\section{ACKNOWLEDGMENTS}

The authors are grateful to Dr. Claudio de Oliveira for his technical assistance during this study. Research supported by FAPESP and CNPq.

\section{REFERENCES}

Abril VV and Duarte JMB (2008). Chromosome polymorphism in the Brazilian dwarf brocket deer, Mazama nana (Mammalia, Cervidae). Genet. Mol. Biol. 31: 53-57.

Abril VV, Carnelossi EA, Gonzalez S and Duarte JM (2010). Elucidating the evolution of the red brocket deer Mazama americana complex (Artiodactyla; Cervidae). Cytogenet. Genome Res. 128: 177-187.

Bogdanov IuF (2003). Variation and evolution of meiosis. Russ. J. Genet. 39: 363-381.

Duarte JMB and Jorge W (1996). Chromosomal polymorphism in several populations of deer (genus Mazama) from Brazil. Arch. Zootec. 45: 281-287.

Duarte JMB and Jorge W (2003). Morphologic and cytogenetic description of the small red brocket (Mazama bororo Duarte, 1996) in Brazil. Mammalia 67: 403-410.

Duarte JM, Gonzalez S and Maldonado JE (2008). The surprising evolutionary history of South American deer. Mol. Phylogenet. Evol. 49: 17-22.

Glover TW and Stein CK (1988). Chromosome breakage and recombination at fragile sites. Am. J. Hum. Genet. 43: 265-273.

Howell WM and Black DA (1980). Controlled silver-staining of nucleolus organizer regions with a protective colloidal developer: a 1-step method. Experientia 36: 1014-1015.

Jones RN and Rees HB (1982). Chromosomes. Academic Press, New York.

Mudry MD, Rahn IM and Solari AJ (2001). Meiosis and chromosome painting of sex chromosome systems in Ceboidea. Am. J. Primatol. 54: 65-78.

Neitzel H (1987). Chromosome Evolution of Cervidae: Karyotypic and Molecular Aspects. In: Cytogenetics, Basic and Applied Aspects (Obe G and Basler A, eds.). Springer Verlag, Berlin, 90-112.

Pack SD, Borodin PM, Serov OL and Searle JB (1993). The X-autosome translocation in the common shrew (Sorex araneus L.): late replication in female somatic cells and pairing in male meiosis. Chromosoma 102: 355-360.

Pathak S and Lin CC (1981). Synaptonemal complex of the sex-autosome trivalent in a male Indian muntjac. Chromosoma 82: 367-376.

Sarria-Perea JA (2004). Comparação entre Alguns Citótipos de Mazama americana (Artiodactyla; Cervidae): Quão Grande é a Diferença entre Eles? Master's thesis, UNESP, Jaboticabal.

Seabright M (1971). A rapid banding technique for human chromosomes. Lancet 2: 971-972.

Sherman JD, Herickhoff LA and Stack SM (1992). Silver staining two types of meiotic nodules. Genome 35: 907-915.

Shi L, Tang L, Ma K and Ma C (1988). Synaptonemal complex formation among supernumerary B chromosomes: an electron microscopy study on spermatocytes of Chinese raccoon dog. Chromosoma 97: 178-183.

Solari AJ (1974). The behavior of the XY pair in mammals. Int. Rev. Cytol. 38: 273-317.

Solari AJ and Pigozzi MI (1994). Fine structure of the XY body in the XY1Y2 trivalent of the bat Artibeus lituratus. Chromosome Res. 2: 53-58.

Switonski M, Gustavsson I and Plöen L (1987a). The nature of the 1;29 translocation in cattle as revealed by synaptonemal complex analysis using electron microscopy. Cytogenet. Cell Genet. 44: 103-111.

Switonski M, Gustavsson I, Höjer K and Plöen L (1987b). Synaptonemal complex analysis of the B-chromosomes in spermatocytes of the silver fox (Vulpes fulvus Desm.). Cytogenet. Cell Genet. 45: 84-92.

Switonski M and Stranzinger G (1998). Studies of synaptonemal complexes in farm mammals - a review. J. Hered. 89: 473-480.

Vargas-Munar DS, Sarria-Perea JA and Duarte JM (2010). Different responses to doxorubicin-induced chromosome aberrations in Brazilian deer species. Genet. Mol. Res. 9: 1545-1549.

Verma RS and Babu A (1995). Human Chromosomes: Principles and Techniques. 2nd edn. McGraw Hill, New York.

Wallace BM, Searle JB and Everett CA (1992). Male meiosis and gametogenesis in wild house mice (Mus musculus domesticus) from a chromosomal hybrid zone; a comparison between "simple" Robertsonian heterozygotes and homozygotes. Cytogenet. Cell Genet. 61: 211-220.

Wallace BM, Searle JB and Everett CA (2002). The effect of multiple simple Robertsonian heterozygosity on chromosome pairing and fertility of wild-stock house mice (Mus musculus domesticus). Cytogenet. Genome Res. 96: 276-286.

Wise D and Nail B (1987). A technique for analysing fish meiotic chromosomes with light and electron microscopies. Copeia 2: 499-503. 